\title{
Altered cardiac expression of peroxisome proliferator-activated receptor-isoforms in patients with hypertensive heart disease
}

\author{
María J. Goikoetxea ${ }^{\mathrm{a}, 1}$, Javier Beaumont ${ }^{\mathrm{a}, 1}$, Arantxa González ${ }^{\mathrm{a}}$, Begoña López ${ }^{\mathrm{a}}$, \\ Ramón Querejeta ${ }^{\mathrm{b}}$, Mariano Larman ${ }^{\mathrm{c}}$, Javier Díez ${ }^{\mathrm{a}, \mathrm{d}, *}$ \\ ${ }^{a}$ Division of Cardiovascular Sciences, Centre for Applied Medical Research, University of Navarra, CIMA, Avda. Pio XII 55, 31008 Pamplona, Spain \\ ${ }^{\mathrm{b}}$ Division of Cardiology, Donostia University Hospital, San Sebastián, Spain \\ ${ }^{\mathrm{c}}$ Division of Haemodynamics, Guipuzcoa Polyclinics, San Sebastián, Spain \\ d Department of Cardiology and Cardiovascular Surgery, University Clinic, School of Medicine, University of Navarra, Pamplona, Spain
}

Received 8 August 2005; received in revised form 19 October 2005; accepted 10 November 2005

Available online 20 December 2005

Time for primary review 14 days

\begin{abstract}
Objective: To investigate whether cardiac expression of the nuclear peroxisome proliferator-activated receptor $\alpha$ (PPAR $\alpha)$ is altered in patients with hypertensive heart disease (HHD).

Methods: We studied endomyocardial septal biopsies from 24 patients with essential hypertension divided into three groups: 6 without left ventricular hypertrophy (LVH) (HT group), 10 with LVH (LVH group), and 8 with LVH and heart failure (HF) (HF group). The expression of two PPAR $\alpha$ isoforms (the native active and the truncated inhibitory) was analyzed by Western blot and reverse transcription polymerase chain reaction (RT-PCR), and two PPAR $\alpha$ target genes were evaluated by RT-PCR. Histomorphological features were evaluated in a second myocardial sample from LVH and HF groups.

Results: Whereas the expression of native PPAR $\alpha$ protein was lower $(p<0.05)$ in LVH and HF groups than in the HT group, truncated PPAR $\alpha$ protein was overexpressed $(p<0.001)$ in the HF group as compared with LVH and HT groups. The mRNA expression of native and truncated PPAR $\alpha$ was similar in the three groups of hypertensives. In addition, a progressive decrease $(p$ for trend $<0.05)$ in the two PPAR $\alpha$ target genes mRNA expression was observed among HT, LVH and HF groups. The amount of truncated PPAR $\alpha$ protein correlates directly with cardiomyocytes apoptosis and inversely with cardiomyocytes density in patients with HHD. In addition, the expression of truncated $\operatorname{PPAR} \alpha$ protein was directly correlated with left ventricular volumes, and inversely with ejection fraction in all hypertensives.

Conclusions: These findings suggest that post-transcriptional regulation of PPAR $\alpha$ isoforms is altered in patients with HHD, namely in those developing HF. An excess of the truncated inhibitory isoform may be involved in hypertensive left ventricular failure and remodeling. (C) 2005 European Society of Cardiology. Published by Elsevier B.V. All rights reserved.
\end{abstract}

Keywords: Hypertension; Heart failure; Hypertrophy; Peroxisome proliferator-activated receptor $\alpha$; Isoforms

\footnotetext{
* Corresponding author. Division of Cardiovascular Sciences, Centre for Applied Medical Research, University of Navarra, CIMA, Avda. Pío XII 55, 31008 Pamplona, Spain. Tel.: +34 948194700x3000; fax: +34 948194716.

E-mail address: jadimar@unav.es (J. Díez).

${ }^{1}$ The first two authors (María J. Goikoetxea and F. Javier Beaumont) contributed equally to this work.
}

\section{Introduction}

Previous studies have shown that myocardial fatty acid utilization is decreased in the failing heart of spontaneously hypertensive rats $[1,2]$ and patients with essential hypertension [3]. It has also been shown that expression of genes encoding cardiac fatty acid oxidation enzymes is coordinately repressed in the myocardium of hypertensive rats and patients with heart failure (HF) [4]. This defect in lipid metabolism can be regarded as a result of alterations in 
peroxisome proliferator-activated receptor $\alpha(\operatorname{PPAR} \alpha)$ transcription factor activity. An abnormally low expression of several fatty acid transporters and mitochondrial fatty acidmetabolizing enzymes has been found in the heart of PPAR $\alpha$ null mice [5]. Thus PPAR $\alpha$ seems to be a critical regulator of myocardial energetics, through the activation of some genes encoding key limiting steps in the fatty acid utilization pathway [6]. Moreover, recent evidences suggest that PPAR $\alpha$ may be an antiinflammatory and antifibrotic transcription factor [7-10]. In fact, the heart from PPAR $\alpha$ null mice shows progressive myocardial degeneration associated with contraction band necrosis, inflammatory infiltrates and diffuse fibrosis besides an abnormally low expression of several fatty acid transporters and mitochondrial fatty acid-metabolizing enzymes [5].

Two variants of the human PPAR $\alpha$ transcription factor have been described. Tugwood et al. [11] and Palmer et al. [12] found a splice variant of PPAR $\alpha$ mRNA lacking exon 6 in human liver. Later on, this variant was also reported in other human tissues including the heart [13]. Whereas the native PPAR $\alpha$ mRNA is known to give rise to an active PPAR $\alpha$ protein $(53 \mathrm{kDa})$, the truncated PPAR $\alpha$ mRNA gives rise to a form of PPAR $\alpha$ protein $(30 \mathrm{kDa})$ which lacks the ligand-binding domain [14]. In addition, recent findings suggest that, upon nuclear translocation, the truncated isoform of PPAR $\alpha$ exerts repressive action on the native PPAR $\alpha$ function, probably through competition for essential coactivators [14].

We have hypothesized that an imbalance between the native active and the truncated inhibitory isoforms of $\operatorname{PPAR} \alpha$ may occur in patients with hypertensive heart disease (HHD). This study was therefore designed to investigate the expression of PPAR $\alpha$ isoforms and the obligate heterodimeric partner retinoid $\mathrm{X}$ receptor $\alpha$ $(\mathrm{RXR} \alpha)$ in the myocardium of patients with HHD. In addition, the expression of PPAR $\alpha$ target genes involved in fatty acid oxidation and histomorphological features of myocardial remodeling were also assessed in tissue samples from the same patients.

\section{Methods}

\subsection{Patients}

All subjects gave written informed consent to participate in the study, and the institutional review committee approved the protocol. The study was approved by the ethical committee of Donostia University Hospital and conformed to the principles of the Helsinki Declaration.

The hypertensive population consisted of 24 Caucasian patients with systolic blood pressure $>139$ and/or diastolic blood pressure of $>89 \mathrm{~mm} \mathrm{Hg}$. All patients had appropriate clinical and laboratory evaluation to exclude secondary hypertension. Other cardiac diseases (e.g., coronary artery disease, aortic stenosis, hypertrophic cardiomyopathy) were excluded after complete medical examination, which included a diagnostic cardiac catheterization. Patients with diabetes mellitus or metabolic syndrome, as defined by the ATPIII criteria, were excluded from the study [15].

Whereas 18 patients exhibited HHD, 6 patients did not (HT group). HHD was defined by the presence of left ventricular hypertrophy (LVH) in the echocardiogram (see below) in the absence of a cause other than arterial hypertension. Whereas 10 patients with HHD did not present medical history or current manifestations of HF (LVH group), 8 patients with HHD had a previous diagnosis of HF (HF group). The diagnosis of HF was made on a clinical basis, by the presence of, at least, 1 major and 2 minor Framingham criteria [16]. After echocardiographic evaluation (see below) the patients were classified into two groups: 4 patients exhibiting an ejection fraction $(\mathrm{EF})<0.40$ (i.e. patients with systolic HF) and 4 patients presenting an $\mathrm{EF} \geq 0.40$ (i.e. patients with diastolic HF). Furthermore, hemodynamic evidence of myocardial failure was obtained in each patient by measuring elevated left ventricular enddiastolic pressure and pulmonary capillary wedge pressure (>12 $\mathrm{mm} \mathrm{Hg}$ in both cases).

\subsection{Assessment of left ventricular dimensions, mass and function}

2D echocardiographic imaging, targeted M-mode recordings and Doppler ultrasound measurements were obtained in each patient. Left ventricular end-diastolic and end-systolic volumes (LVEDV and LVESV, respectively) were calculated according to Doughty et al [17]. Left ventricular mass index (LVMI) was calculated as previously described [18]. The presence of LVH was established when LVMI was $>111 \mathrm{~g} /$ $\mathrm{m}^{2}$ for men and $>106 \mathrm{~g} / \mathrm{m}^{2}$ in women [19]. The following pulsed Doppler measurements were obtained: maximum early transmitral velocity in diastole; maximum late transmitral velocity in diastole; the deceleration time of the early mitral filling wave; and isovolumic relaxation time. Left ventricular EF was calculated according to Quinones et al. [20].

\subsection{Sample acquisition}

Transvenous endomyocardial biopsies were taken from the middle area of the interventricular septum with a bioptome, Cordis $960 \mathrm{~mm}$ (7F), under fluoroscopic guidance after angiographic examination, as previously reported [18]. Two biopsies were taken in each intervention. The biopsy procedure was well tolerated in all cases and no complications were recorded. The first sample was divided into two smaller pieces and frozen separately in liquid nitrogen following different processes for protein or mRNA obtention. Protein was extracted in lysis buffer $(7 \mathrm{~mol} / \mathrm{L}$ urea, $2 \mathrm{~mol} / \mathrm{L}$ thiourea, $4 \%$ Chaps, $1 \%$ dithiothreitol), and mRNA was initially isolated with TRIzol (Invitrogen) and subsequently purified using QIAGEN's RNeasy Total RNA 
Isolation kit. The second myocardial sample was immediately fixed in $4 \%$ buffered formalin, embedded in paraffin, and serially sectioned in 4- $\mu \mathrm{m}$-thick sections for the histomorphological studies.

Human liver tissue, kindly provided by Dr. José Ignacio Riezu-Boj, was used as a positive control in analyzing the expression of the two PPAR $\alpha$ isoforms. The hepatic sample was processed in the same way as the cardiac samples.

\section{4. $m R N A$ studies}

To identify the presence of the splice variant of PPAR $\alpha$ mRNA, reverse transcription polymerase chain reaction (RT-PCR) followed by sequentiation was performed. Reverse transcription was performed with $200 \mathrm{ng}$ of total RNA and two primers flanking exon 6 were used to amplify human cDNA: (i) 5'-GCCAGTATTGTCGATTTCACAAGT-3' corresponding to sequences 674-697 of the human PPAR $\alpha$ cDNA, located in exon 5; (ii) $5^{\prime}-$ TCCTTGTTCTGGATGCCATTG-3' corresponding to sequences 996-1016 of the human PPAR $\alpha$ cDNA, located in exon 7. PCR products were separated by electrophoresis, showing two different fragments, one of $343 \mathrm{bp}$ and other about $140 \mathrm{bp}$ (Fig. 1). The smaller fragment was excised from the gel and cloned into a pCR 2.1 vector for sequencing. The DNA sequence of this fragment was determined using the dideoxy chain-termination method [21]. This fragment contained the published sequence of exon 5 followed by exon 7, lacking exon 6 [22] (Fig. 1).

To corroborate the presence of the truncated $\operatorname{PPAR} \alpha$ mRNA, a specific TaqMan fluorescent probe that recognizes the last nucleotides of exon 5 and the first nucleotides of exon 7 of PPAR $\alpha$ cDNA was designed. The fluorescent signal of this probe can only be detected when exon 5 is followed by exon 7, exon 6 being absent. The fluorescent signal was analyzed with an ABI PRISM 7000 Sequence Detection System. This splice variant was detected in all individuals tested.
mRNA levels of the two PPAR $\alpha$ isoforms and the PPAR $\alpha$ target genes carnitine palmitoyl transferase-I (CPTI) and long-chain 3-hydroxyacyl-CoA dehydrogenase (LCHAD) [23] were analyzed by real time quantitative RT-PCR. Reverse transcription was performed with $200 \mathrm{ng}$ of total RNA. Real-time PCR was performed with an ABI PRISM 7000 Sequence Detection System by using specific TaqMan MGB fluorescent probes. Data are expressed as arbitrary units (AU) relative to constitutive $18 \mathrm{~S}$ ribosomal RNA.

\subsection{Protein studies}

To analyze the expression of both isoforms of PPAR $\alpha$ and $\mathrm{RXR} \alpha$ proteins, aliquots containing $10 \mu \mathrm{g}$ of total protein were diluted in $4 \times$ sample buffer $(40 \% \beta$ mercaptoethanol, $8 \%$ SDS, $40 \%$ glycerol, $0.025 \%$ bromophenol blue, and $0.25 \mathrm{mmol} / \mathrm{L}$ Tris, $\mathrm{pH} 6.4$ ), separated by electrophoresis on $10 \%$ polyacrylamide gel and transferred onto nitrocellulose membranes. To identify the presence of the truncated PPAR $\alpha$ protein a Western blot followed by an immunoblot using two different antibodies were performed in every sample. Specific rabbit and goat polyclonal antibodies (Santa Cruz Technologies) against the amino-terminal and the carboxy-terminal portions of $\operatorname{PPAR} \alpha$, respectively, were incubated at a dilution of $1: 1000$. Bands were detected by incubation with peroxidase-conjugated anti-rabbit IgG (Amersham) at a dilution of 1:5000 and anti-goat IgG (Amersham) at a dilution of 1:50000. Two protein bands were detected using the antibody against the amino-terminal portion of PPAR $\alpha$ : one of $53 \mathrm{kDa}$ and another of $30 \mathrm{kDa}$. When the same membranes were reprobed with antibody against the carboxy-terminal portion, no signal of $30 \mathrm{kDa}$ was detected. The two PPAR $\alpha$ isoforms (e.g., the native and the truncated) are therefore expressed in the human myocardium at the protein level. Since both isoforms of $\operatorname{PPAR} \alpha$ have been described in the human liver [14], hepatic tissue was used as a positive control for the two antibodies. Western blot of the hepatic tissue showed two

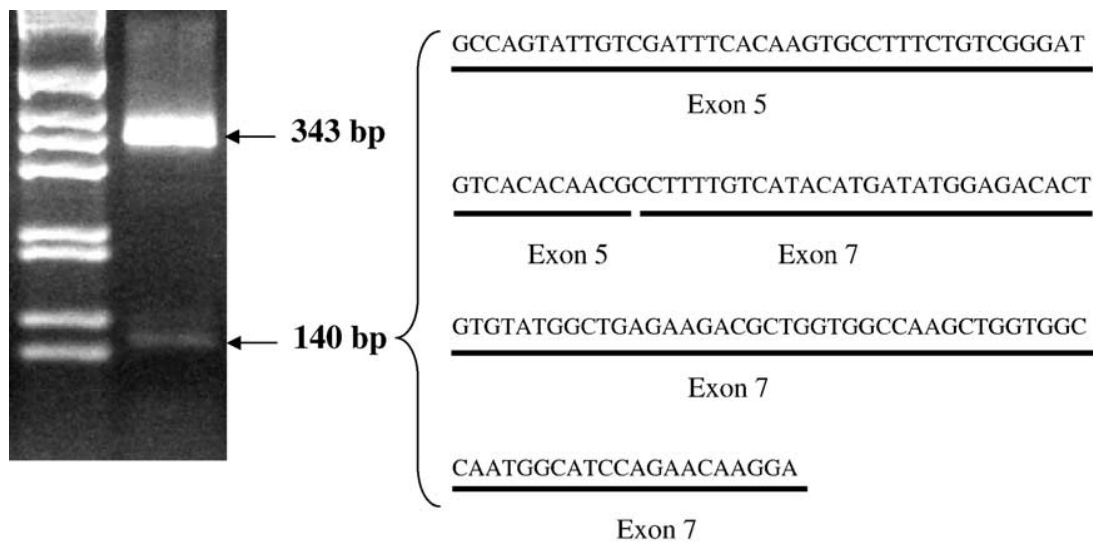

Fig. 1. Left panel: Fragments of $343 \mathrm{bp}$ and of $140 \mathrm{bp}$ obtained by amplification of cDNA with the primers flanking exon 6 and electrophoresis. Right panel: Nucleotide sequence of the $140 \mathrm{bp}$ fragment, with the corresponding exons. 
bands of $53 \mathrm{kDa}$ and $30 \mathrm{kDa}$ using the amino-terminal antibody and only one band of $53 \mathrm{kDa}$ with the carboxyterminal antibody.

The expression of $\mathrm{RXR} \alpha$ was assessed by using a specific rabbit polyclonal antibody (Santa Cruz Biotechnologies) at a dilution of 1:1000 and peroxidase-conjugated anti-rabbit IgG (Amersham) antibody at a dilution of 1:5000.

Both PPAR $\alpha$ isoforms and $\mathrm{RXR} \alpha$ protein expression was visualized with the ECL-Plus chemiluminescence system (Amersham) and autoradiograms analyzed using an automatic densitometer (Quantity One, Bio-Rad). The blots were reprobed with a monoclonal $\beta$-actin antibody (Sigma) as a control for loading. Data are expressed as arbitrary densitometric units (ADU) relative to $\beta$-actin expression.

\subsection{Histomorphologic study}

We analyzed some myocardial histomorphological alterations involved in the transition from LVH to HF (e.g. apoptosis, inflammation and fibrosis) in 7 patients from the LVH group and 8 from the HF group.

Apoptosis was assayed by the terminal deoxynucleotidyl transferase (TdT) reaction. DNA end-labeling (TUNEL) methodology was performed as previously described [24]. The discrimination between cardiomyocytes and non-cardiomyocytes was performed according to cytological characteristics of the different cell types [25]. Apoptotic indexes were calculated as the ratio between the number of TUNEL positive nuclei and the total number of nuclei for each type of cardiac cell evaluated. The determination of the total number of cardiomyocytes and non-cardiomyocytes was performed on a serial section from the one employed for the TUNEL technique, stained with Masson's trichrome. Cardiomyocyte and non-cardiomyocyte densities were also analyzed. To asses myocardial inflammation, COX-2 protein expression was analyzed by immunohistochemistry using a specific goat polyclonal antibody (Santa Cruz Biotechnologies) at a dilution of 1:100 and biotinilated anti-goat IgG (Amersham) antibody at a dilution of 1:200. The staining of myocardial deposit of collagen fibers was performed as previously reported [18]. The fraction of myocardial volume occupied by fibrillar collagen (CVF) and COX-2 immunostained area were determined by quantitative morphometry with an automated image analysis system (AnalySYS, Soft Imaging System GmbH, Hammer). The histomorphologic studies were performed by two pathologists blinded to the other characteristics of the patients under study.

\subsection{Statistical analysis}

To analyze the differences among the three groups of patients, a 1-way ANOVA followed by Scheffé's test was performed once normality had been proven (ShapiroWilks test); otherwise, the non-parametric Kruskal-Wallis test followed by a Mann-Whitney $U$ test (adjusting the $\alpha$ level by Bonferroni's inequality) was used. To assess any tendency in the parameters measured as HHD develops and progresses, the linear test for trend was used. Differences between patients with LVH and patients with HF were tested by a Student's $t$ test for unpaired data once normality was demonstrated; otherwise, a non-parametric test (Mann-Whitney $U$ test) was used. The correlation between continuously distributed variables was tested by univariate regression analysis. Values are expressed as mean \pm S.E.M. A value of $p<0.05$ was considered statistically significant.

\section{Results}

\subsection{Clinical characteristics of hypertensive patients}

The clinical characteristics of the three groups of patients are presented in Table 1. Two patients in the HT group and five patients of the LVH group were receiving antihypertensive medication as monotherapy. No significant differ-

Table 1

Clinical parameters determined in hypertensives

\begin{tabular}{|c|c|c|c|}
\hline Parameter & HT group & LVH group & HF group \\
\hline Age, years & $63 \pm 2$ & $59 \pm 2$ & $66 \pm 4$ \\
\hline Gender, $\mathrm{M} / \mathrm{F}$ & $2 / 4$ & $6 / 4$ & $5 / 3$ \\
\hline BMI, $\mathrm{kg} / \mathrm{m}^{2}$ & $24.8 \pm 1.6$ & $30.7 \pm 2.3$ & $28.4 \pm 1.1$ \\
\hline Loop diuretics, $n$ & 1 & 1 & 6 \\
\hline ACEI or ARA, $n$ & - & - & 8 \\
\hline$\beta$-Blockers, $n$ & - & 1 & 7 \\
\hline$\alpha$-Blockers, $n$ & - & 1 & - \\
\hline $\mathrm{Ca}^{2+}$ antagonists, $n$ & 1 & 2 & - \\
\hline $\mathrm{SBP}, \mathrm{mm} \mathrm{Hg}$ & $162 \pm 8$ & $168 \pm 7$ & $146 \pm 5$ \\
\hline DBP, mm Hg & $89 \pm 5$ & $94 \pm 3$ & $88 \pm 3$ \\
\hline $\mathrm{HR}$, beats/min & $69 \pm 4$ & $70 \pm 3$ & $69 \pm 2$ \\
\hline LVEDV, ml & $114.76 \pm 11.95$ & $122.66 \pm 10.49$ & $167.28 \pm 15.76^{\mathrm{a}, \mathrm{b}}$ \\
\hline LVESV, ml & $34.72 \pm 6.65$ & $32.33 \pm 4.88$ & $91.32 \pm 18.18^{\mathrm{a}, \mathrm{c}}$ \\
\hline LVMI, $\mathrm{g} / \mathrm{m}^{2}$ & $82.1 \pm 4.8$ & $151.4 \pm 12.0^{\mathrm{d}}$ & $145.39 \pm 7.8^{\mathrm{d}}$ \\
\hline IVRT, ms & $104.2 \pm 2.3$ & $107.1 \pm 6.3$ & $109.5 \pm 4.3$ \\
\hline $\mathrm{V}_{\mathrm{E}} / \mathrm{V}_{\mathrm{A}}$ & $1.13 \pm 0.14$ & $0.78 \pm 0.08$ & $1.38 \pm 0.37$ \\
\hline $\mathrm{T}_{\mathrm{DEC}}, \mathrm{ms}$ & $216.7 \pm 9.2$ & $226.6 \pm 22.3$ & $207.2 \pm 19.2$ \\
\hline $\mathrm{EF}, \%$ & $73.7 \pm 3.1$ & $68.7 \pm 1.9$ & $43.9 \pm 5.6^{\mathrm{c}, \mathrm{d}}$ \\
\hline
\end{tabular}

HT, hypertension; HF, heart failure; LVH, left ventricular hypertrophy; BMI, body mass index; ACEI, angiotensin-converting enzyme inhibitor; ARA, angiotensin II type 1 receptor antagonist; SBP, systolic blood pressure; DBP, diastolic blood pressure; HR, heart rate; LVEDV, left ventricular end diastolic volume; LVESV, left ventricular end systolic volume; LVMI, left ventricular mass index; IVRT, isovolumic relaxation time; $\mathrm{V}_{\mathrm{E}}$, maximal early transmitral velocity in diastole; $\mathrm{V}_{\mathrm{A}}$, maximal late transmitral velocity in diastole; $\mathrm{T}_{\mathrm{DEC}}$, deceleration time; $\mathrm{EF}$, ejection fraction.

Values are expressed as mean \pm S.E.M. or number of subjects.

${ }^{\text {a }} p<0.05$, compared with HT group.

b $p<0.05$, compared with LVH group.

c $p<0.01$, compared with LVH group.

d $p<0.01$, compared with HT group. 
ences in blood pressure were found between treated and untreated patients in HT and LVH groups (data not shown). Most patients in the HF group were treated with the combination of a loop diuretic, a beta-blocker and either an angiotensin converting enzyme inhibitor or an angiotensin II type 1 receptor antagonist. The values of LVMI were higher in LVH and HF groups than in the HT group. The EF was lower in the HF group than in LVH and HT groups. The left ventricle volumes were higher in the HF group than in LVH and HT groups.

\subsection{Expression of PPAR $\alpha$ isoforms and $R X R \alpha$}

Compared with the HT group $(1.16 \pm 0.24$ arbitrary densitometric units, ADU), the expression of native $\operatorname{PPAR} \alpha$ protein was decreased $(p<0.05)$ in the LVH group $(0.52 \pm 0.10 \mathrm{ADU})$ and the HF group $(0.58 \pm 0.06$ ADU) (Fig. 2). No difference was found in native PPAR $\alpha$ protein expression between LVH and HF groups. The expression of truncated $\operatorname{PPAR} \alpha$ protein was higher $(p<0.001)$ in the HF group $(2.95 \pm 0.32 \mathrm{ADU})$ than in the LVH group $(0.89 \pm 0.16 \mathrm{ADU})$ and the HT group $(0.17 \pm 0.09$ ADU) (Fig. 2). Although the expression of truncated PPAR $\alpha$ protein did tend to be higher in the LVH group than in the HT group, the differences did not reach statistical significance. As a consequence, a progressive decrease ( $p$ for trend $<0.01$ ) was observed in the native PPAR $\alpha$ : truncated PPAR $\alpha$ ratio among the three groups of patients (HT: 4.17 \pm 1.85 ADU; LVH: 0.78 $\pm 0.21 \mathrm{ADU}$; HF: $0.20 \pm 0.01$ ADU). No significant differences in the expression of the two isoforms of PPAR $\alpha$ were found between patients with systolic HF (native PPAR $\alpha$ : $0.59 \pm 0.04$ ADU; truncated PPAR $\alpha: 2.92 \pm 0.55$ ADU) and diastolic HF (native $\operatorname{PPAR} \alpha: 0.57 \pm 0.11$ ADU; truncated PPAR $\alpha: 2.98 \pm 0.42$ ADU).

The expression of $\mathrm{RXR} \alpha$ protein did tend to be lower in the HF group (13.98 $\pm 0.88 \mathrm{ADU})$ than in the LVH group (17.08 \pm 1.75 ADU) and the HT group (17.59 \pm 5.57 ADU) but the differences did not reach statistical significance.

The expression of native PPAR $\alpha$ mRNA was similar in the three groups of patients (HT:1.01 \pm 0.09 AU; LVH: $1.08 \pm 0.12 \mathrm{AU}$; HF: $1.28 \pm 0.13 \mathrm{AU})$. In addition, no significant changes were observed in the expression of truncated PPAR $\alpha$ mRNA among the three groups of patients (HT: $0.62 \pm 0.09$ AU; LVH: $0.43 \pm 0.03$; HF: $0.62 \pm$ 0.09 AU).

\subsection{Expression of PPAR $\alpha$ target genes}

As an approach to evaluate whether the observed differences in the native PPAR $\alpha$ :truncated PPAR $\alpha$ ratio were accompanied by changes in PPAR $\alpha$ transcriptional activity, mRNA expression of the PPAR $\alpha$ target genes CPTI and LCHAD was assessed. A progressive decrease ( $p$ for trend $<0.05)$ in CPT-I mRNA and LCHAD mRNA was observed among HT, LVH and HF groups (Fig. 3).

\subsection{Assessment of myocardial apoptosis, inflammation and fibrosis}

Data on the measured histomorphological parameters are presented in Table 2. The HF group showed increased $(p<0.01)$ cardiomyocyte apoptotic index compared with the LVH group. The non-cardiomyocyte apoptotic index did tend to be higher in the HF group than in the LVH group but the difference was not statistically significant. Whereas
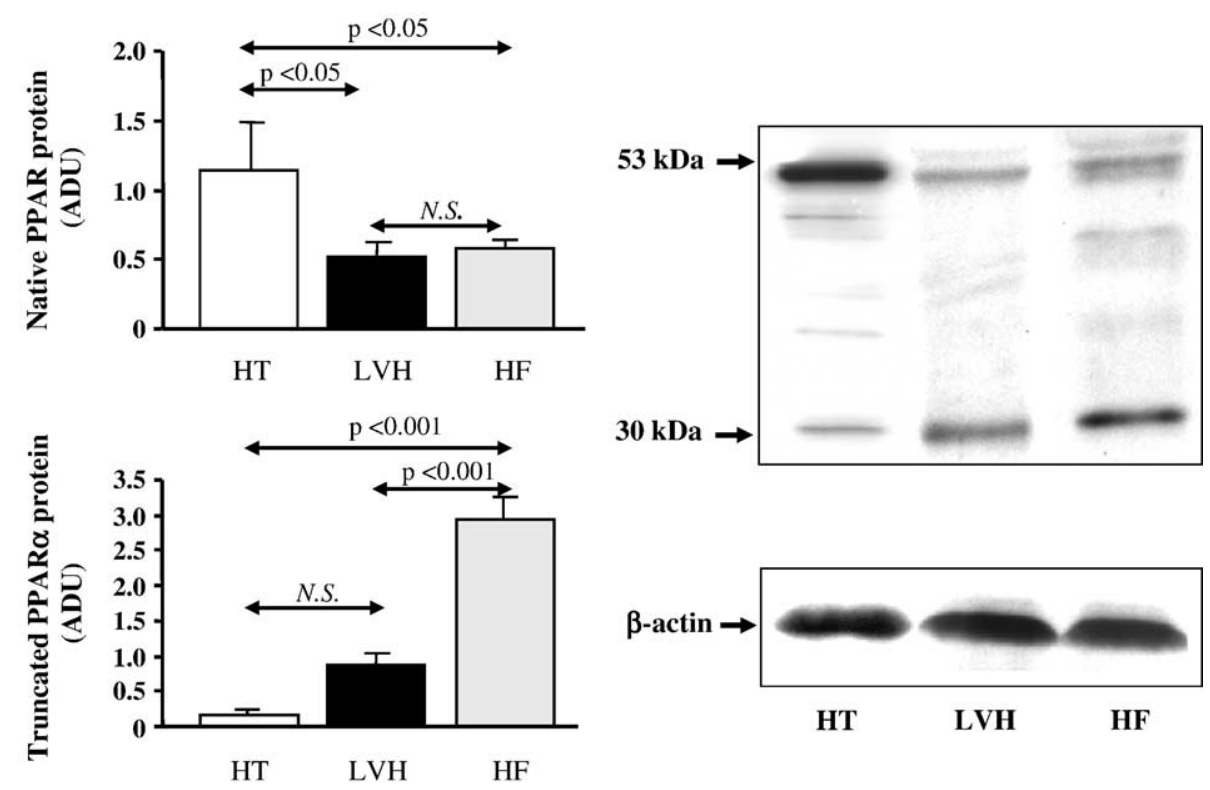

Fig. 2. Left panels: Histograms showing the expression of native ( $53 \mathrm{kDa})$ and truncated ( $30 \mathrm{kDa})$ PPAR $\alpha$ protein isoforms in the myocardium of HT, LVH and HF groups. Right panel: Representative Western blots obtained in one subject from each group. ADU, arbitrary densitometric units. 

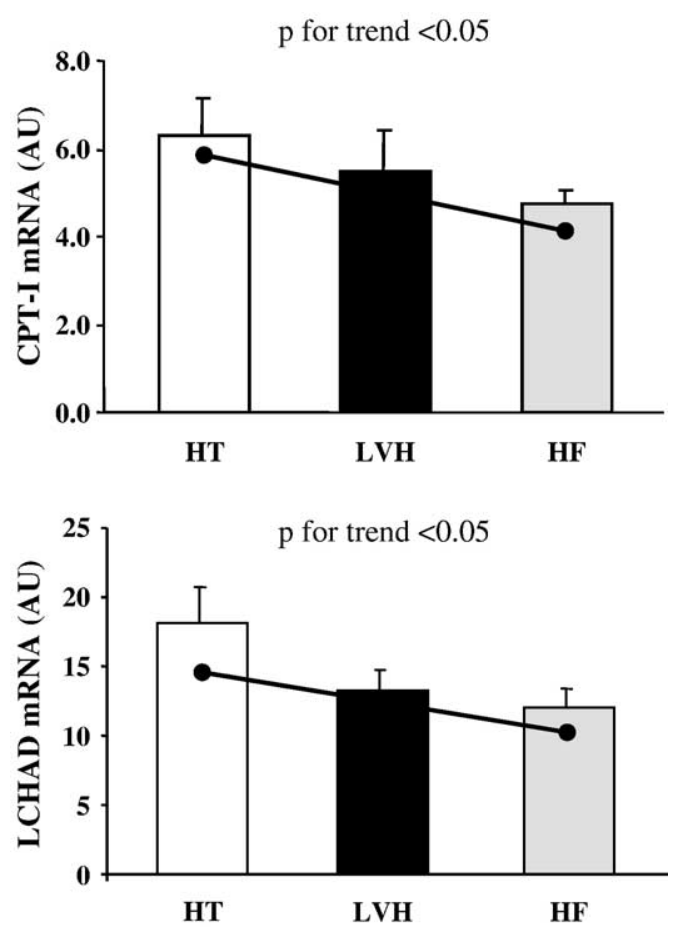

Fig. 3. Upper panel: Histograms showing the mRNA expression of the PPAR $\alpha$ target gene CPT-I in the myocardium of HT, LVH and HF groups. Lower panel: Histograms showing the mRNA expression of the PPAR $\alpha$ target gene LCHAD in the myocardium of HT, LVH and HF groups. AU, arbitrary units.

cardiomyocyte density was lower $(p<0.01)$ in the HF group than in the LVH group, no differences were observed in non-cardiomyocyte density between HF and LVH groups. COX-2 expression was higher $(p<0.05)$ in the HF group than in the LVH group. CVF was increased $(p<0.05)$ in the HF group compared with the LVH group.

\subsection{Correlational analysis}

Truncated PPAR $\alpha$ protein was inversely correlated with EF $(r=-0.652, p<0.01)$ (Fig. 4) and directly correlated with LVEDV $(r=0.538, p<0.01)$ and LVESV $(r=0.579$, $p<0.01$ ) in all patients (Fig. 5). Truncated PPAR $\alpha$ protein was directly correlated with the cardiomyocyte apoptotic index $(r=0.572, p<0.05)$ and inversely correlated with the

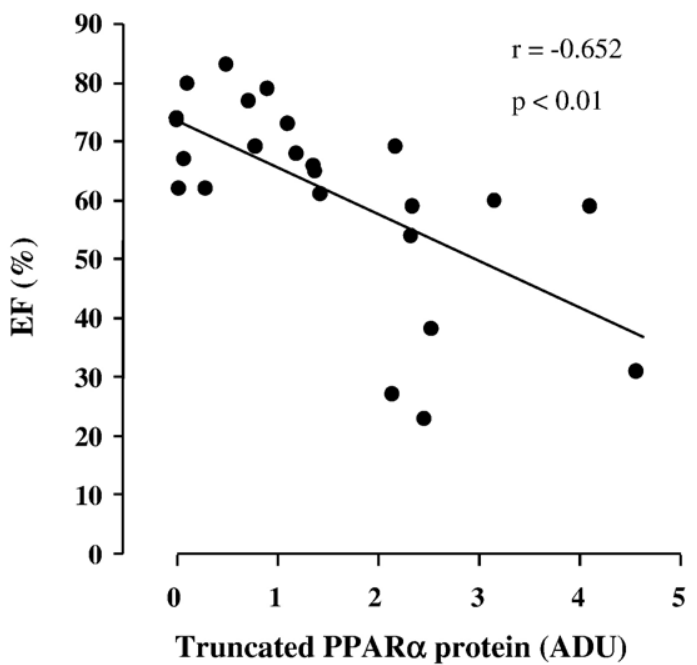

Fig. 4. Inverse correlation $(y=-8.35 x+74.04)$ between truncated PPAR $\alpha$ protein and ejection fraction (EF) in all patients. ADU, arbitrary densitometric units.

cardiomyocyte density $(r=-0.695, p<0.01)$ in patients with HHD (Fig. 6). No significant correlations were found between the native PPAR $\alpha$ protein and the different parameters tested in this study. CPT-I mRNA expression was directly correlated with $\mathrm{EF}(r=0.640, p<0.05)$.

\section{Discussion}

The main findings of this study can be summarized as follows: (1) the human heart expresses both the native active and the truncated inhibitory isoforms of PPAR $\alpha$ protein, (2) whereas the expression of native PPAR $\alpha$ protein is diminished in patients with HHD, the truncated PPAR $\alpha$ protein is overexpressed only in those patients with HHD who develop HF, (3) the expression of the PPAR $\alpha$ target genes decreases in parallel with the development and progression of HHD, and (4) the truncated PPAR $\alpha$ protein is associated with the structural, geometric and functional deterioration of the hypertensive left ventricle.

A variant human PPAR $\alpha$ mRNA species has been identified, which is generated by a post-transcriptional mechanism involving alternative splicing resulting in the

Table 2

Myocardial apoptosis, inflammation and fibrosis

\begin{tabular}{lcc}
\hline Parameter & LVH group & HF group \\
\hline CM apoptotic index (positive nuclei $/ 10^{6}$ nuclei) & $2107 \pm 781$ & $11215 \pm 1722^{\mathrm{a}}$ \\
Non-CM apoptotic index (positive nuclei $/ 10^{6}$ nuclei) & $2031 \pm 567$ & $4177 \pm 878$ \\
CM density (nuclei $/ \mathrm{mm}^{2}$ ) & $604 \pm 50$ & $423 \pm 33^{\mathrm{a}}$ \\
Non-CM density $\left(\right.$ nuclei $\left./ \mathrm{mm}^{2}\right)$ & $1095 \pm 100$ & $1171 \pm 69$ \\
COX-2 $(\%)$ & $10.86 \pm 1.02$ & $20.84 \pm 4.49^{\mathrm{b}}$ \\
CVF $(\%)$ & $5.47 \pm 0.51$ & $8.44 \pm 1.19^{\mathrm{b}}$ \\
\hline
\end{tabular}

$\mathrm{LVH}$, means left ventricular hypertrophy; HF, heart failure; CM, cardiomyocyte; COX-2, cyclo-oxygenase 2; CVF, collagen volume fraction.

Values are expressed as mean \pm S.E.M.

${ }^{\text {a }} p<0.01$, compared with LVH group.

b $p<0.05$, compared with LVH group. 

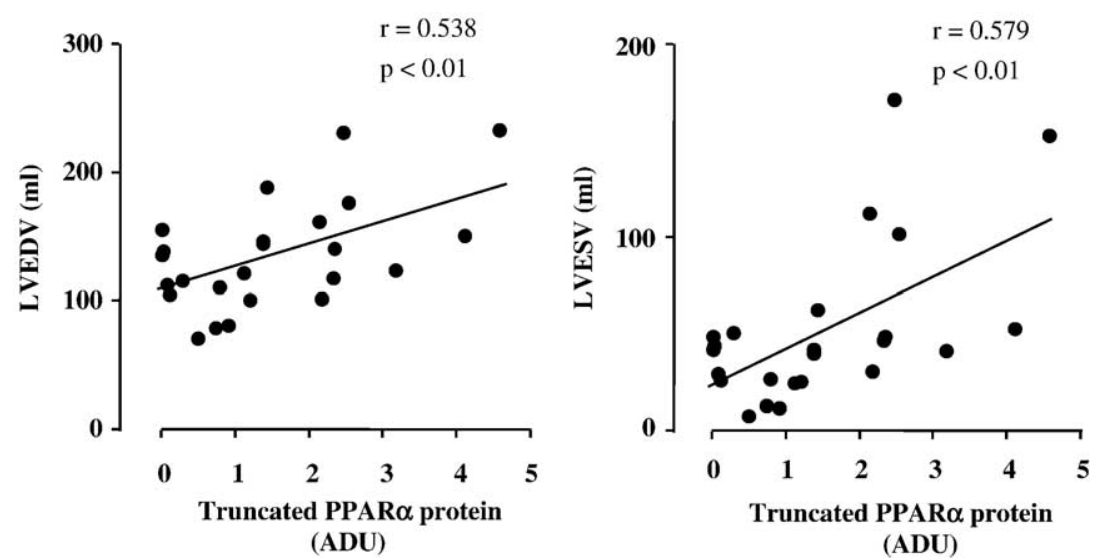

Fig. 5. Left panel: Direct correlation $(y=17.54 x+109.58)$ between truncated PPAR $\alpha$ protein and left ventricular end-diastolic volume (LVEDV) in all patients. Right panel: Direct correlation $(y=18.75 x+24.81)$ between truncated PPAR $\alpha$ protein and left ventricular end-systolic volume (LVESV) in all patients. ADU, arbitrary densitometric units.

skipping of exon $6[11,12]$. This splice variant of PPAR $\alpha$ mRNA has been identified in a number of human tissues, including the heart [13]. In this study, we detect the PPAR $\alpha$ mRNA variant in all of the individuals examined, which suggests that exon skipping is associated with the processing of the human PPAR $\alpha$ pre-mRNA, and that it does not reflect a rare allele. Exon skipping has been observed for transcripts of other genes and often leads to circular RNAs formed by the excised exons [26]. However, neither the mechanisms leading to the excision of the exon and the formation of the circular RNA nor the factors that contribute to this process have been clearly defined.

Data presented in the current study demonstrate that the regulation of the two cardiac isoforms of PPAR $\alpha$ protein is altered in a different way in patients with HHD. In fact, whereas repression of the native PPAR $\alpha$ isoform is associated with the development of $\mathrm{LVH}$, overexpression of the truncated PPAR $\alpha$ isoform seems to be linked to the transition from LVH to HF. Therefore, although a diminished expression of native PPAR $\alpha$ has been reported previously in the hypertrophied left ventricle of animals submitted to cardiac pressure overload $[27,28]$ and patients with HF [29], this is the first demonstration of alterations of truncated PPAR $\alpha$ in the hypertensive heart. In addition, the origin of these alterations seems to be post-transcriptional since native and truncated mRNA PPAR $\alpha$ expression was not modified along the three groups of hypertensives tested. However, further studies are necessary to investigate potential post-trancriptional mechanisms (e.g. changes in mRNA stability) influencing the two isoforms of PPAR $\alpha$ in the hypertensive myocardium.

Nevertheless, overexpression of the truncated PPAR $\alpha$ may also be a consequence of the loss of cardiac function. In fact, generation by alternative splicing of isoforms with repressive activity on the native isoform has been reported for other nuclear receptors (i.e., the glucocorticoid receptor and the thyroid hormone receptor) [30,31] as a general mechanism to diversify and to adapt receptor action on pathophysiological conditions. Clearly, further studies are necessary to elucidate the significance and relevance of truncated PPAR $\alpha$ protein in the hypertensive heart.

As suggested by in vitro studies [14], the association of diminished active PPAR $\alpha$ isoform with enhanced inhibitory PPAR $\alpha$ isoform may compromise PPAR $\alpha$-dependent

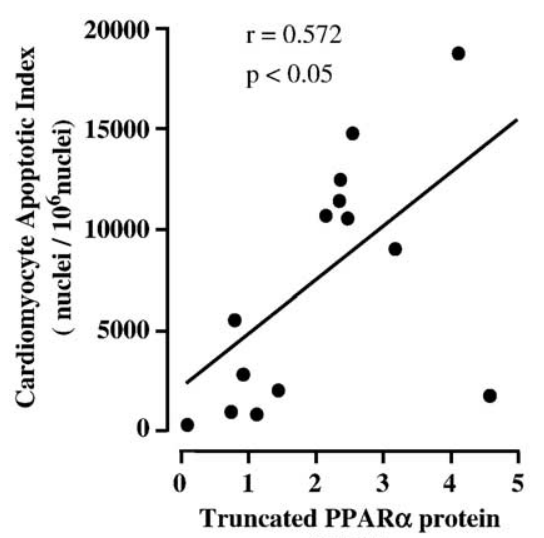

(ADU)

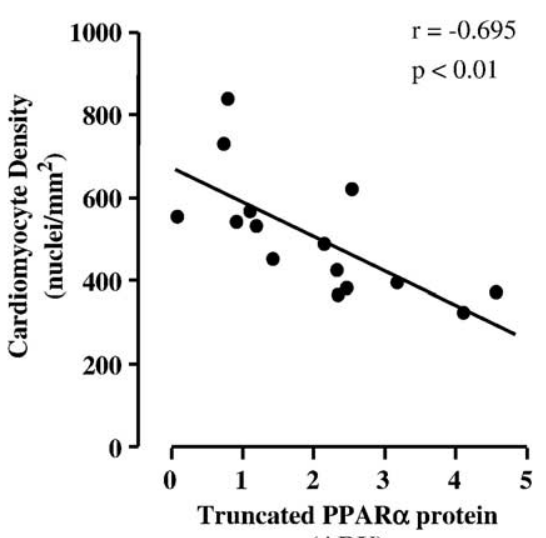

(ADU)

Fig. 6. Left panel: Direct correlation $(y=2629 x+1945)$ between the expression of truncated PPAR $\alpha$ protein and cardiomyocyte apoptotic index. Right panel: Inverse correlation $(y=-78 x+663)$ between the expression of truncated PPAR $\alpha$ protein and cardiomyocyte density. ADU, arbitrary densitometric units. 
transcriptional activity in the failing heart. In fact, we observed that a progressive decrease in native PPAR $\alpha$ : truncated PPAR $\alpha$ ratio was associated with a progressive decrease in the expression of the PPAR $\alpha$ target genes CPTI and LCHAD involved in fatty acid transport and oxidation. A continuous decrease in fatty acid oxidation has been found in hypertensives with LVH with and without HF compared with control subjects [3]. Since ATP availability and function of the heart are closely linked, it is reasonable to assume that deactivation of PPAR $\alpha$ leading to diminished fatty acid oxidation and reduced production of ATP might be involved in the compromise of cardiac function in HF. In support of this possibility, we observed a direct association between CPT-I expression and ejection fraction. Thus it is tempting to speculate that progressive impairment of PPAR $\alpha$ transactivation activity accompanies the development of HHD and may contribute to its progression to $\mathrm{HF}$.

Alternatively, PPAR $\alpha$ alterations could be involved in the transition from LVH to HF through the facilitation of some structural features characteristic of myocardial remodelling. In fact, a number of experimental evidences suggest that depressed myocardial PPAR $\alpha$ expression and/or activity could be linked with the development of inflammation and fibrosis [7-10]. In addition, it has been shown that PPAR $\alpha$ null mice develop massive cardiomyocyte accumulation of fatty acid intermediates [5]. Some of these compounds, e.g. ceramide, can induce reactive oxygen species accumulation, inducible nitric oxide synthase expression and cardiomyocyte apoptosis [32]. Our findings showing associations of depressed PPAR $\alpha$ activity with increased inflammation, fibrosis and cardiomyocytes apoptosis in the failing hypertensive heart could provide support to this view. Furthermore, the associations here reported of truncated $\operatorname{PPAR} \alpha$ with cardiomyocyte apoptosis and density on the one hand, and left ventricular dimensions and systolic performance on the other hand, raise the possibility that this molecule might contribute directly to the development of HF in hypertensive patients. In fact, it has been proposed that increased cardiomyocyte apoptosis present in the failing hypertensive heart could contribute to the impairment of systolic function due to the loss of contractile mass, and to the dilatation of the left ventricular chamber through side-toside slippage of cardiomyocytes [33,34].

\subsection{Limitations of the study}

This was a study involving a small number of patients. Furthermore, no studies in normotensive subjects were performed. However, because of the nature of the goals under investigation this design is appropriate. In addition, it must be recognized that therapy with different types of drugs in the three groups of patients may have confounded the findings and their interpretation. For instance, angiotensin converting enzyme inhibitors have been reported to interfere with PPAR $\alpha$ expression in the vascular wall [35] although no data are available yet on their effects on cardiac PPAR $\alpha$. Nevertheless, one must consider that, since such therapies are standard for hypertension and HF, it would have been unreasonable to withdraw them for the purposes of this research. Moreover, it is important to note that no patient was under treatment with drugs that modify PPAR $\alpha$ expression and/or activity (i.e., thiazolidinediones, fibrates and statins). We performed biopsies of the right side of the interventricular septum to assess the molecular and cellular effects of left ventricular pressure loading. However, as shown by others [36], lesions present in the septum in postmortem tissue from hypertensive human hearts are representative of lesions existing in the free wall. Finally, we are aware that the real time RT-PCR method here used is not sensitive enough to detect small mRNA differences. However, the small amount of mRNA available in the samples forced us to select this method for mRNA expression measurement.

In summary, we report for the first time that HHD is associated with an excess of the truncated inhibitory PPAR $\alpha$ isoform related to the native active isoform, which is accompanied by a diminished expression of a PPAR $\alpha$ target enzymes involved in fatty acid utilization. Interestingly, these alterations evolve in parallel with both the development myocardial structural remodelling and the progression from compensated LVH to HF. In addition, results here presented suggest that the truncated PPAR $\alpha$ isoform may be directly involved in the pathophysiology of the hypertensive left ventricle. Albeit preliminary and descriptive in nature, the data here presented set the stage for further studies intended to test the above hypothesis.

\section{Acknowledgements}

The authors thank Sonia Martínez and Dr M. Ujué Moreno for expert technical support.

María J. Goikoetxea received a research training grant (BF104.305) from the Department of Education, Universities and Research of the Basque Government. This work has been partially founded by the Red Temática de Investigación Cardiovascular (RECAVA, C03/01), Ministry of Health, Spain, by a grant from the Fondo de Investigaciones Sanitarias (PI04/0017), Ministry of Health, Spain, and by the arrangement between FIMA and UTE-CIMA project.

\section{References}

[1] Christe ME, Rodgers RL. Altered glucose and fatty acid oxidation in hearts of the spontaneously hypertensive rat. J Mol Cell Cardiol 1994;26:1371-5.

[2] Hajri T, Ibrahimi A, Coburn CT, Knapp Jr FF, Kurtz T, Pravenec M, et al. Defective fatty acid uptake in the spontaneously hypertensive rat is a primary determinant of altered glucose metabolism, hyperinsulinemia, and myocardial hypertrophy. J Biol Chem 2001;276:23661-6.

[3] de las Fuentes L, Herrero P, Peterson LR, Kelly DP, Gropler RJ, Davila-Roman VG. Myocardial fatty acid metabolism: independent 
predictor of left ventricular mass in hypertensive heart disease. Hypertension 2003;41:83-7.

[4] Sack MN, Rader TA, Park S, Bastin J, McCune SA, Kelly DP. Fatty acid oxidation enzyme gene expression is downregulated in the failing heart. Circulation 1996;94:2837-42.

[5] Watanabe K, Fujii H, Takahashi T, Kodama M, Aizawa Y, Ohta Y, et al. Constitutive regulation of cardiac fatty acid metabolism through peroxisome proliferator-activated receptor alpha associated with agedependent cardiac toxicity. J Biol Chem 2000;275:22293-9.

[6] Finck BN, Kelly DP. Peroxisome proliferator-activated receptor alpha (PPARalpha) signaling in the gene regulatory control of energy metabolism in the normal and diseased heart. J Mol Cell Cardiol 2002;34:1249-57.

[7] Iglarz M, Touyz RM, Viel EC, Paradis P, Amiri F, Diep QN, et al. Peroxisome proliferator-activated receptor-alpha and receptor-gamma activators prevent cardiac fibrosis in mineralocorticoid-dependent hypertension. Hypertension 2003;42:737-43.

[8] Diep QN, Benkirane K, Amiri F, Cohn JS, Endemann D, Schiffrin EL. PPAR alpha activator fenofibrate inhibits myocardial inflammation and fibrosis in angiotensin II-infused rats. J Mol Cell Cardiol 2004;36:295-304.

[9] Ogata T, Miyauchi T, Sakai S, Irukayama-Tomobe Y, Goto K, Yamaguchi I. Stimulation of peroxisome-proliferator-activated receptor alpha (PPAR alpha) attenuates cardiac fibrosis and endothelin-1 production in pressure-overloaded rat hearts. Clin Sci (Lond) 2002; $103: 284 \mathrm{~S}-8 \mathrm{~S}$.

[10] Ogata T, Miyauchi T, Sakai S, Takanashi M, Irukayama-Tomobe Y, Yamaguchi I. Myocardial fibrosis and diastolic dysfunction in deoxycorticosterone acetate-salt hypertensive rats is ameliorated by the peroxisome proliferator-activated receptor-alpha activator fenofibrate, partly by suppressing inflammatory responses associated with the nuclear factor-kappa-B pathway. J Am Coll Cardiol 2004;43: $1481-8$.

[11] Tugwood JD, Aldridge TC, Lambe KG, Macdonald N, Woodyatt NJ Peroxisome proliferator-activated receptors: structures and function. Ann NY Acad Sci 1996;804:252-65.

[12] Palmer CN, Hsu MH, Griffin KJ, Raucy JL, Johnson EF. Peroxisome proliferator activated receptor-alpha expression in human liver. Mol Pharmacol 1998;53:14-22.

[13] Hanselman JC, Vartanian MA, Koester BP, Gray SA, Essenburg AD, Rea TJ, et al. Expression of the mRNA encoding truncated PPAR alpha does not correlate with hepatic insensitivity to peroxisome proliferators. Mol Cell Biochem 2001;217:91-7.

[14] Gervois P, Torra IP, Chinetti G, Grotzinger T, Dubois G, Fruchart JC, et al. A truncated human peroxisome proliferator-activated receptor alpha splice variant with dominant negative activity. Mol Endocrinol 1999;13:1535-49.

[15] Executive Summary of The Third Report of The National Cholesterol Education Program (NCEP) Expert Panel on Detection, Evaluation, And Treatment of High Blood Cholesterol In Adults (Adult Treatment Panel III). JAMA 2001;285:2486-97.

[16] Ho KK, Pinsky JL, Kannel WB, Levy D. The epidemiology of heart failure: the Framingham Study. J Am Coll Cardiol 1993;22:6A-13A.

[17] Doughty RN, Whalley GA, Gamble G, MacMahon S, Sharpe N. Left ventricular remodeling with carvedilol in patients with congestive heart failure due to ischemic heart disease. Australia-New Zealand Heart Failure Research Collaborative Group. J Am Coll Cardiol 1997; 29:1060-6.

[18] Querejeta R, Varo N, Lopez B, Larman M, Artinano E, Etayo JC, et al. Serum carboxy-terminal propeptide of procollagen type $\mathrm{I}$ is a marker of myocardial fibrosis in hypertensive heart disease. Circulation 2000;101:1729-35.

[19] Ganau A, Devereux RB, Roman MJ, de Simone G, Pickering TG, Saba PS, et al. Patterns of left ventricular hypertrophy and geometric remodeling in essential hypertension. J Am Coll Cardiol 1992;19: $1550-8$.

[20] Quinones MA, Pickering E, Alexander JK. Percentage of shortening of the echocardiographic left ventricular dimension. Its use in determining ejection fraction and stroke volume. Chest 1978;74: $59-65$.

[21] Sanger F, Nicklen S, Coulson AR. DNA sequencing with chainterminating inhibitors. Biotechnology 1992;24:104-8.

[22] Sher T, Yi HF, McBride OW, Gonzalez FJ. cDNA cloning, chromosomal mapping, and functional characterization of the human peroxisome proliferator activated receptor. Biochemistry 1993;32: 5598-604.

[23] Barger PM, Kelly DP. PPAR signaling in the control of cardiac energy metabolism. Trends Cardiovasc Med 2000;10:238-45.

[24] González A, López B, Ravassa S, et al. Stimulation of cardiac apoptosis in essential hypertension: potential role of angiotensin II. Hypertension 2002;39:75-80.

[25] Burkitt H.G. Y.B., Heath JW. Wheater's functional histology. Edinburgh: Churchill Livingstone; 1996.

[26] Zaphiropoulos PG. Exon skipping and circular RNA formation in transcripts of the human cytochrome P-450 2C18 gene in epidermis and of the rat androgen binding protein gene in testis. Mol Cell Biol 1997; 17:2985-93.

[27] Barger PM, Brandt JM, Leone TC, Weinheimer CJ, Kelly DP. Deactivation of peroxisome proliferator-activated receptor-alpha during cardiac hypertrophic growth. J Clin Invest 2000;105:1723-30.

[28] Young ME, Laws FA, Goodwin GW, Taegtmeyer H. Reactivation of peroxisome proliferator-activated receptor alpha is associated with contractile dysfunction in hypertrophied rat heart. J Biol Chem 2001;276:44390-5.

[29] Karbowska J, Kochan Z, Smolenski RT. Peroxisome proliferatoractivated receptor alpha is downregulated in the failing human heart. Cell Mol Biol Lett 2003;8:49-53.

[30] Oakley RH, Sar M, Cidlowski JA. The human glucocorticoid receptor beta isoform. Expression, biochemical properties, and putative function. J Biol Chem 1996;271:9550-9.

[31] Koenig RJ, Lazar MA, Hodin RA, Brent GA, Larsen PR, Chin WW, et al. Inhibition of thyroid hormone action by a non-hormone binding cerbA protein generated by alternative mRNA splicing. Nature 1989;337:659-61.

[32] Bielawska AE, Shapiro JP, Jiang L, et al. Ceramide is involved in triggering of cardiomyocyte apoptosis induced by ischemia and reperfusion. Am J Pathol 1997;151:1257-63.

[33] Fortuño MA, González A, Ravassa S, López B, Díez J. Clinical implications of apoptosis in hypertensive heart disease. Am J Physiol Heart Circ Physiol 2003;284:H1495-1506.

[34] González A, Fortuño MA, Querejeta R, Ravassa S, Lopez B, Lopez N, et al. Cardiomyocyte apoptosis in hypertensive cardiomyopathy. Cardiovasc Res 2003;59:549-62.

[35] da Cunha V, Tham DM, Martin-McNulty B, Deng G, Ho JJ, Wilson DW, et al. Enalapril attenuates angiotensin II-induced atherosclerosis and vascular inflammation. Atherosclerosis 2005;178:9-17.

[36] Pearlman ES, Weber KT, Janicki JS, Pietra GG, Fishman AP. Muscle fiber orientation and connective tissue content in the hypertrophied human heart. Lab Invest 1982;46:158-64. 